\title{
ACS \\ Production of Poly(vinyl alcohol) (PVA) Fibers with Encapsulated Natural Deep Eutectic Solvent (NADES) Using Electrospinning
}

\author{
Francisca Mano, ${ }^{\dagger}$ Ivo M. Aroso, ${ }^{\ddagger}, \S$ Susana Barreiros, ${ }^{\dagger}$ João Paulo Borges, ${ }^{\prime \prime}$ Rui L. Reis, ${ }^{\ddagger}$,
}

Ana Rita C. Duarte, ${ }^{\ddagger}$, and Alexandre Paiva* ${ }^{\dagger}$

${ }^{\dagger}$ LAQV-REQUIMTE, Departamento de Química, Faculdade de Ciências e Tecnologia, Universidade NOVA de Lisboa, $2829-516$ Caparica, Portugal

${ }^{\ddagger}$ BB’s Research Group-Biomaterials, Biodegradable and Biomimetic, University of Minho, Headquarters of the European Institute of Excellence on Tissue Engineering and Regenerative Medicine, Avepark, 4805-017 Taipas, Guimarães, Portugal

${ }^{\S}$ ICVS/3B's PT Government Associate Laboratory, 4710-057 Braga/Guimarães, Portugal

"CENIMAT/I3N, Departamento de Ciência dos Materiais, Faculdade de Ciências e Tecnologia, FCT, Universidade NOVA de Lisboa, 2829-516 Caparica, Portugal

ABSTRACT: Functionalized electrospun fibers are of great interest for biomedical applications such as in the design of drug delivery systems. Nevertheless, in some cases the molecules of interest have poor solubility in water or have high melting temperatures. These drawbacks can be overcome using deep eutectic solvents. In this work, poly(vinyl alcohol) (PVA), a common biodegradable biopolymer, was used to produce new functionalized fibers with the eutectic mixture choline chloride:citric acid in a molar ratio of (1:1) ChCl:CA (1:1), which was used as a model system. Fibers were produced from an aqueous solution with $7.8 \%(\mathrm{w} / \mathrm{v})$ and $9.8 \%(\mathrm{w} / \mathrm{v})$ of $95 \%$ hydrolyzed PVA and a $2 \%(\mathrm{v} / \mathrm{v})$ of $\mathrm{ChCl}: \mathrm{CA}$ (1:1). Smooth, uniform fibers with an average diameter of $0.4 \mu \mathrm{m}$ were obtained with a content of 19.8 wt \% of ChCl:CA (1:1) encapsulated.

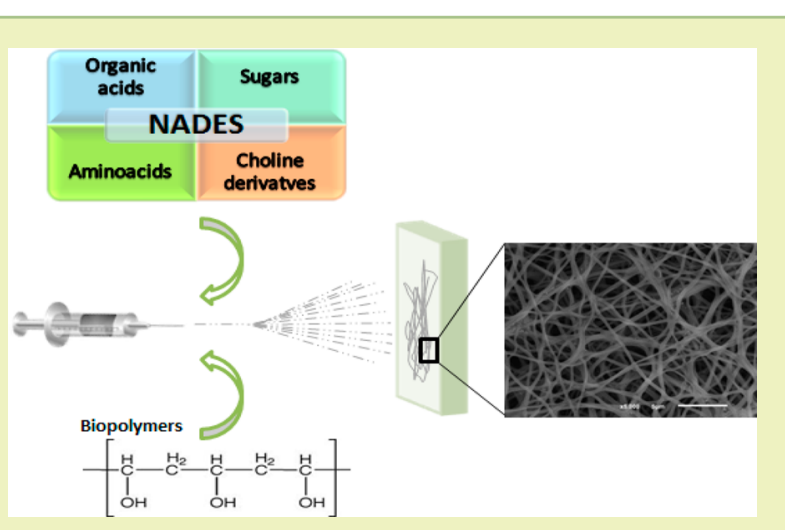

KEYWORDS: Natural Deep-eutectic solvents, Poly(vinyl alcohol), Electrospinning

\section{INTRODUCTION}

Growing global awareness of environmental issues has led to the development of new processes that better conform to the Twelve Principles of Green Technology. Considered to be green solvents, ionic liquids (ILs) have gained significant attention in the scientific community. Because of their physicochemical properties ${ }^{1,2}$ and ability to solvate organic species, these new solvents were presented as substitutes for VOCs (volatile organic compounds). ${ }^{1}$ However, the green character of ILs has often been challenged due to their poor biodegradability, biocompatibility, and sustainability. ${ }^{2,3}$

Deep-eutectic solvents (DES) appeared at the beginning of the 21 st century as an alternative to ILs in various areas, ${ }^{4}$ such as electrochemistry, ${ }^{5}$ extraction, ${ }^{6}$ or biocatalysis. ${ }^{7}$ They present the typical behavior of an eutectic mixture, because they result from the mixture of two or more compounds. ${ }^{4}$ For a specific ratio of combination of components, it is possible to create a final mixture with a lower melting point than that of each individual component. ${ }^{4,8}$ The compounds used to make DES are usually based on a quaternary ammonium salt, e.g., choline chloride, as well as carboxylic acids or other hydrogen-bond donors. ${ }^{2,8}$ The melting point of the mixture decreases as result of the complexation that occurs between the salt and a hydrogen bond acceptor, ${ }^{8}$ resulting in the formation of a liquid.
Although they share similar physical properties with ILs, DES are cheaper to produce, biodegradable, and have low toxicity. ${ }^{2}$ This is mainly due to the use of cheap and renewable compounds as source materials. ${ }^{2,4}$ Because the synthesis of DES is basically a mixing process, they do not need any postsynthesis purification. Their purity depends only on the purity of the individual components. ${ }^{8}$ These properties make DES a viable alternative to ILs. Still, DES present some challenges. In some cases, DES have high viscosities and can even be solid at room temperature, which poses handling problems. $^{9}$

To explain biological reactions that could not happen in water or lipid media, ${ }^{10}$ Dai and co-workers put forward the possibility of those reactions taking place in DES media. They reported on a large number of stable mixtures that resulted in a new subclass of DES, termed natural deep-eutectic solvents (NADES). ${ }^{9,10}$ On the basis of natural compounds involved in metabolic pathways, NADES are mainly made of primary metabolites. There are more than $10^{6}$ possible combinations of

Received: July 1, 2015

Revised: September 14, 2015 
compounds that form NADES, which makes NADES designer solvents, in much the same way as ILs., ${ }^{9,10}$

The main advantage of using natural compounds to form DES is the pharmaceutically acceptable toxicity profile and biocompatibility that ensues, ${ }^{10-12}$ thus extending the applications of these solvents to the biomedical field.

ILs are known to improve the processability of biopolymers, by having a plasticizing effect on the polymer and by increasing its conductivity. The latter is of special importance when processing biopolymers by electrospinning to produce fibers. ${ }^{13-19}$ More recently, DES have also been reported to be effective biopolymer modifiers, by decreasing the glass transition temperature of the polymer. ${ }^{16,17}$

Wang et al. ${ }^{17}$ have shown that the plasticizing effect of choline chloride:urea in cellulose allowed the production of flexible and transparent cellulose films. Martins et al. ${ }^{16}$ were able to enhance the processability of starch-based blends by supercritical foaming using different DES. Electrospinning consists of applying an electric field to a polymeric solution in order to charge it. ${ }^{18}$ With the charge repulsion, the solution is ejected from a needle (at a positive high voltage) to a grounded collector, where it is deposited. ${ }^{18}$ This technique has gained interest for polymer processing, mainly because it allows the control of fiber morphology, diameter, and even porosity. ${ }^{19-21}$ Moreover, the ability to produce fibers at the nanoscale and to impregnate or encapsulate biomolecules, makes electrospinning an ideal technique for the production of fibers for drug delivery or tissue engineering. ${ }^{22}$

Poly(vinyl alcohol) (PVA) is obtained through the hydrolysis of poly(vinyl acetate). ${ }^{23}$ PVA is cheap, and widely used industrially. ${ }^{24}$ It exhibits good biocompatibility ${ }^{23-25}$ and nontoxicity. ${ }^{24,25}$ PVA fibers have been extensively studied in pharmaceutical formulations, ${ }^{26}$ drug delivery, ${ }^{23,24}$ cosmetics, ${ }^{26}$ biomedical materials, ${ }^{27,28}$ among others. ${ }^{29,30}$

To the best of our knowledge, DES have never been applied in the production of biopolymer fibers by electrospinning. This paper reports on the production of PVA fibers by electrospinning, using with choline chloride:citric acid NADES.

\section{EXPERIMENTAL SECTION}

Materials. Choline chloride $(\mathrm{ChCl} ; \geq 98 \%)$ was purchased from Sigma-Aldrich. Poly(vinyl alcohol) (PVA; 95\% hydrolyzed, Mv 95000) was acquired through Acros Organics. Citric acid (CA; $\geq 99 \%)$ was obtained from Merck. All chemicals were used without further purification.

Preparation of Electrospinning Solutions. A ChCl:CA NADES solution was prepared by weighing choline chloride and citric acid on a 1:1 molar ratio, mixing the two components and leaving the mixture under stirring at $45{ }^{\circ} \mathrm{C}$ until a clear liquid was obtained. The mixture remained in the liquid state after cooling to room temperature.

For the electrospinning process, two aqueous solutions of PVA with $7.8 \%(\mathrm{w} / \mathrm{v})$ and $9.8 \%(\mathrm{w} / \mathrm{v})$ were prepared at $80{ }^{\circ} \mathrm{C}$. After complete dissolution of PVA and cooling of each solution to room temperature, $2 \%(\mathrm{v} / \mathrm{v}) \mathrm{ChCl}$ :CA NADES was added under stirring until a clear solution was obtained.

Electrospinning Process. A $1 \mathrm{~mL}$ syringe fitted with a 23-gauge needle $(0.41 \mathrm{~mm})$ was used for the injection of the solution. The syringe was placed on a syringe pump (KDS100) with controlled feed rate. The needle was electrically linked to a conducting ring, with a diameter of $15 \mathrm{~cm}$. Both were directly connected to a high voltage supply (Glassman EL $30 \mathrm{kV}$ ). Fiber collection was carried out with the help of a fixed collector coated with aluminum foil. Temperature and humidity were controlled and maintained at $27-29^{\circ} \mathrm{C}$ and $45-50 \%$ respectively. For temperatures above $30{ }^{\circ} \mathrm{C}$ and humidity below $40 \%$, the solution formed a droplet at the end of the needle, preventing jet formation. Thus, no fibers were formed at those conditions. Electrospinning parameters, i.e., polymer concentration, voltage, distance between the needle and the collector, feed rate, temperature and humidity were optimized.

Rheological Properties. The rheological properties of the PVA/ NADES were measured with a Malvern Kinexus Prot, using parallel plates, with a diameter of $2 \mathrm{~cm}$, at $25{ }^{\circ} \mathrm{C}$. All measurements were obtained in steady-state conditions. The results are the average of at least three measurements and are represented as the average \pm standard deviation.

Fiber Analysis. Scanning Electron Microscopy (SEM). The morphology of the fibers was analyzed on a JEOL SEM, model JSM-6010LV. The samples were fixed with mutual conductive adhesive tape on aluminum stubs and covered with gold/palladium using a sputter coater.

Transmission Electron Microscopy (TEM). Results were obtained with a Hitachi 8100 TEM, equipped with ThermoNoran light elements and EDS detector.

Fourier Transform Infrared Spectroscopy (FTIR). FTIR was used to detect the presence of functional groups in the fibers. FITR results were obtained using a Tensor 27 FTIR Spectrometer, from Bruker Optics GmbH, with the help of appropriate software (OPUS 6.0).

Thermogravimetric Analysis (TGA). Fiber composition was also determined by thermogravimetric analysis, performed with a TGA analyzer (model TA Q500, TA Instruments). The samples were equilibrated at $30^{\circ} \mathrm{C}$ to determine the initial sample mass, followed by constant heating to $650^{\circ} \mathrm{C}$, at $10^{\circ} \mathrm{C} \mathrm{min}^{-1}$, under an inert atmosphere $\left(\mathrm{N}_{2}\right.$, flow rate of $\left.40 \mathrm{~cm}^{3} \mathrm{~min}^{-1}\right)$. The weight loss was recorded and analyzed with TA universal analysis software.

Mechanical Properties. Tensile mechanical analysis of the fibers was performed using an INSTRON 5540 (Instron Int. Ltd., High Wycombe, UK) universal testing machine with a load cell of $1 \mathrm{kN}$. The dimensions of the specimens used were $5 \mathrm{~cm}$ of length, $2 \mathrm{~cm}$ width, and $0.5 \mathrm{~mm}$ of thickness. The load was placed midway between the supports with a span (L) of $3 \mathrm{~cm}$. The crosshead speed was $1.5 \mathrm{~mm}$ $\mathrm{min}^{-1}$. Tensile tests were conducted up to the samples rupture. The results presented are the average of at least three measurements for three different specimens, and the results are presented as the average \pm standard deviation.

\section{RESULTS AND DISCUSSION}

Electrospinning Parameter Optimization. Electrospinning parameters can be divided into three main classes: environmental parameters (temperature and humidity), working parameters (flow rate, distance to collector, voltage) and solution parameters (concentration, molecular weight of the polymer, viscosity).

Because of its production process, PVA is available at various degrees of hydrolysis. This characteristic affects its mechanical properties, water resistance and even dissolution. ${ }^{31}$ At higher degrees of hydrolysis, as in the present study, the dissolution of PVA in water is more difficult, requiring higher temperatures, but on the other hand the polymer exhibits higher mechanical resistance, when compared to PVA obtained with a higher degree of hydrolysis. ${ }^{31}$

A range of PVA concentrations has been tested for electrospinning. $^{23,31,32}$ Two values were chosen for this study, namely $7.8 \%(\mathrm{w} / \mathrm{v})$ and $9.8 \%(\mathrm{w} / \mathrm{v})$, respectively. ChCl:CA NADES at $2 \%(\mathrm{v} / \mathrm{v})$ was added to each PVA solution. When the $7.8 \%(\mathrm{w} / \mathrm{v})$ PVA solution was used, the fibers obtained had bead imperfections, which disappeared when the concentration of PVA was increased to $9.8 \%(\mathrm{w} / \mathrm{v})$, yielding fibers with a smooth and uniform morphology.

The rheology behavior of the $7.8 \%(\mathrm{w} / \mathrm{v})$ and $9.8 \%(\mathrm{w} / \mathrm{v})$ PVA solutions (containing 2\% (v/v) NADES) was determined and the flow curves (viscosity vs shear stress) are presented in Figure 1. The results obtained show that, for the shear stress 


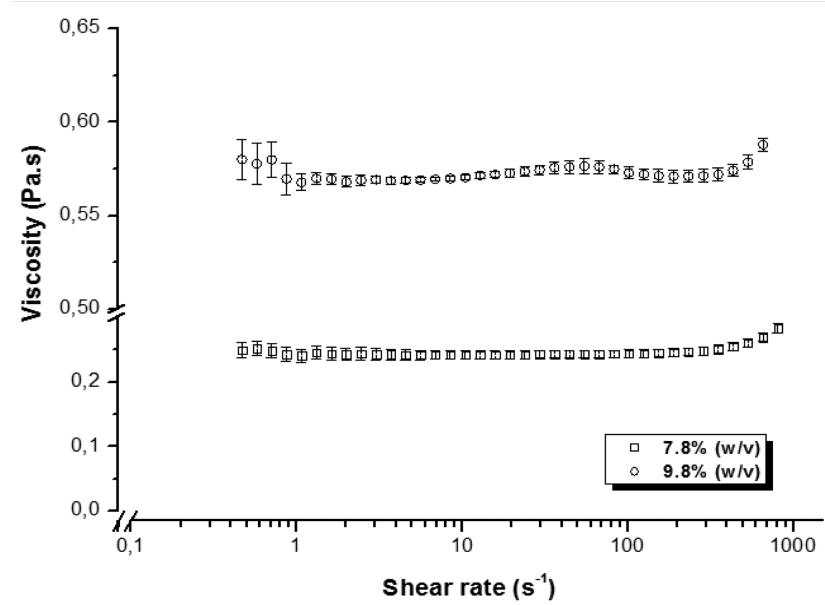

Figure 1. Effect of PVA concentration $(w / v)$ on the viscosity of the electrospinning solutions. The solutions contained $2 \%(\mathrm{v} / \mathrm{v}) \mathrm{ChCl}: \mathrm{CA}$ NADES. The measurements were performed at $25^{\circ} \mathrm{C}$.

range tested, the viscosity remains constant, which is a typical behavior of Newtonian fluids. ${ }^{33}$ For these shear stress conditions, the polymer chains align with the direction of the flow reducing entanglements. The viscosity for the $7.8 \%$ and 9.8\% (w/v) PVA solutions was measured to be, respectively, $0.24\left( \pm 1.8 \times 10^{-4}\right)$ and $0.57\left( \pm 5.5 \times 10^{-4}\right) \mathrm{Pa} \cdot \mathrm{s}$. The viscosity increase is a result of the higher polymer concentration.

Throughout the electrospinning process, there are strong mechanical stresses applied to the solution and the shear stress will change with time and electrospinning conditions. The Newtonian behavior that these solutions present assures that the properties will remain constant during all processing stages.

A solution containing $9.8 \%(\mathrm{w} / \mathrm{v})$ PVA and $2 \%(\mathrm{v} / \mathrm{v})$ $\mathrm{ChCl}$ :CA (1:1) NADES was used for the optimization of the electrospinning parameters. Contrarily to the solution of $9.8 \%$ $(\mathrm{w} / \mathrm{v})$ PVA where smooth fibers were obtained, for the $7.8 \%$ $(\mathrm{w} / \mathrm{v})$ PVA solution, the formation of beads along the fiber was observed.

Voltage and flow rate are directly linked to the distance between the needle and the fiber collector. Therefore, voltage, flow rate and distance were optimized simultaneously. Voltage was varied between 15 and $25 \mathrm{kV}$, flow rate between 0.1 and 0.2 $\mathrm{mL} / \mathrm{min}$, and distance between 11 and $18 \mathrm{~cm}$. The latter had a significant influence on the shape of the fibers. For distances lower than $11 \mathrm{~cm}$, particles were formed instead of fibers. Distances higher than $16 \mathrm{~cm}$ fibers started to breakdown. The various parameters tested can be seen in Table 1 .

Fiber Characterization. The morphology of PVA fibers with ChCl:CA was observed using SEM and TEM. Results can be seen in Figure 2 and Figure 3. SEM shows that the fibers have a smooth surface and a uniform diameter distribution. Some regions evidence fiber fusion, which can be attributed to the presence of $\mathrm{ChCl}$ :CA. Unlike PVA, this NADES is highly hygroscopic, which prevents complete evaporation of the solvent. As shown in Figure 2, fibers obtained have a diameter distribution of $0.4 \pm 0.1 \mu \mathrm{m}$ being considered submicrometric fibers.

In TEM, the interaction between the electron beam and the sample creates image contrast. A region appears darker, or lighter, according to its density. TEM images for the PVA fibers with $\mathrm{ChCl}$ :CA NADES are shown in Figure 3. PVA appears
Table 1. Electrospinning Conditions (Environmental and Working Parameters) When Using a $9.8 \%(w / v)$ PVA Solution Containing 2\% (v/v) ChCl:CA (1:1), for Electrospinning Optimization

\begin{tabular}{|c|c|c|c|c|c|}
\hline temperature & $\begin{array}{l}\text { humidity } \\
\text { (\%) }\end{array}$ & $\begin{array}{l}\text { flow } \\
\text { rate } \\
(\mathrm{mL} / \mathrm{h})\end{array}$ & $\begin{array}{l}\text { distance } \\
(\mathrm{cm})\end{array}$ & $\begin{array}{c}\text { voltage } \\
(\mathrm{kV})\end{array}$ & $\begin{array}{l}\text { electrospinning } \\
\text { result }\end{array}$ \\
\hline $27{ }^{\circ} \mathrm{C}$ & 48 & 0.1 & 11 & 22.5 & $\begin{array}{l}\text { some beads; not } \\
\text { very lined } \\
\text { fibers; drop } \\
\text { formation }\end{array}$ \\
\hline \multirow[t]{3}{*}{$28-29^{\circ} \mathrm{C}$} & $40-45$ & 0.2 & 11 & 15 & $\begin{array}{l}\text { drops formation } \\
\text { and not ligned } \\
\text { fibers }\end{array}$ \\
\hline & & & 15 & & some beads \\
\hline & & & 16 & 17.5 & $\begin{array}{l}\text { no beads; ligned } \\
\text { fibers; some } \\
\text { drops }\end{array}$ \\
\hline $28{ }^{\circ} \mathrm{C}$ & $45-50$ & 0.2 & 16 & 20 & $\begin{array}{l}\text { uniform and } \\
\text { smooth fibers }\end{array}$ \\
\hline
\end{tabular}

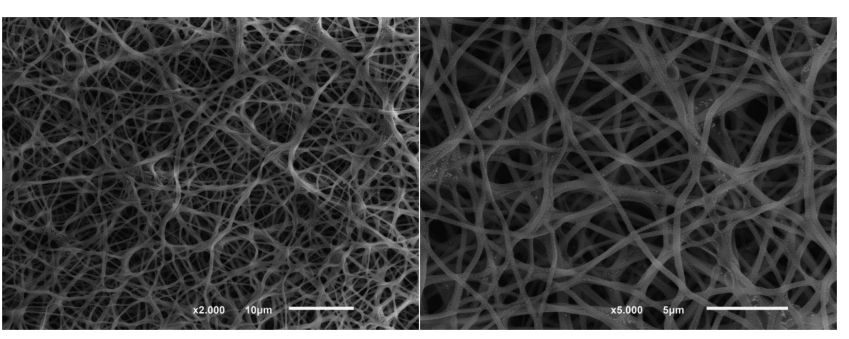

Figure 2. SEM images of PVA fibers obtained with a 9.8\% (w/v) PVA, $2 \%(\mathrm{v} / \mathrm{v}) \mathrm{ChCl}: \mathrm{CA}$ solution. Electrospinning conditions: $0.2 \mathrm{~mL} / \mathrm{h}$ flow rate, $20 \mathrm{kV}$ voltage, $16 \mathrm{~cm}$ needle to collector distance, $25^{\circ} \mathrm{C}$, and $45 \%$ humidity.

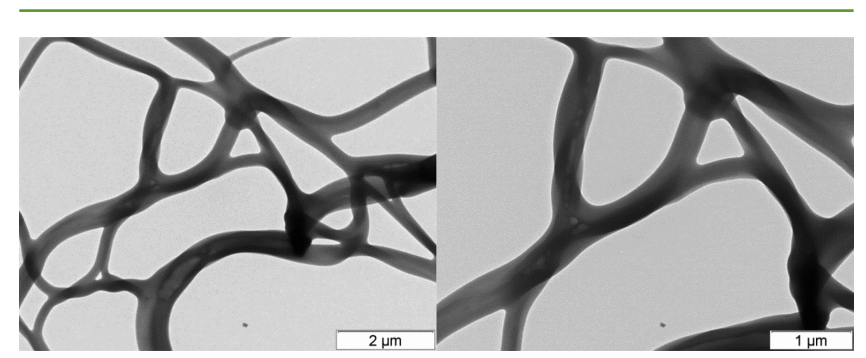

Figure 3. TEM images of $9.8 \%(\mathrm{w} / \mathrm{v})$ PVA, $2 \%(\mathrm{v} / \mathrm{v}) \mathrm{ChCl}$ :CA fibers. Electrospinning conditions as in Figure 2.

lighter due to its lower density, confirming that $\mathrm{ChCl}$ :CA is inside the fibers.

FTIR it was used as a complementary technique. The spectra of PVA, ChCl:CA NADES and electrospun fibers are shown in Figure 4. The PVA spectrum shows a broad $\mathrm{H}$-bonded, $\mathrm{O}-\mathrm{H}$ stretching band ${ }^{34}$ at $\nu=3443 \mathrm{~cm}^{-1}$, and a broad $\mathrm{C}-\mathrm{H}$ alkyl stretching band ${ }^{34}$ at $\nu=2923 \mathrm{~cm}^{-1}$. The ChCl:CA NADES spectrum evidence mostly broad $\mathrm{C}-\mathrm{H}$ and $\mathrm{O}-\mathrm{H}$ stretching bands between 3500 and $2800 \mathrm{~cm}^{-1}$. The $\mathrm{C}=\mathrm{O}$ stretching band is also visible due to the presence of citric acid ( $\nu=1731$ $\mathrm{cm}^{-1}$ ).

The FTIR spectrum of the fibers combines features of the spectra of the individual components, with particular relevance for the absorption band $\nu=1716.33 \mathrm{~cm}^{-1}$, assigned to the carbonyl group of the citric acid, thus proving the presence of the NADES.

FTIR analysis has already proven that there is an interaction between PVA and $\mathrm{ChCl}: \mathrm{CA}$, meaning that $\mathrm{ChCl}$ :CA is present 


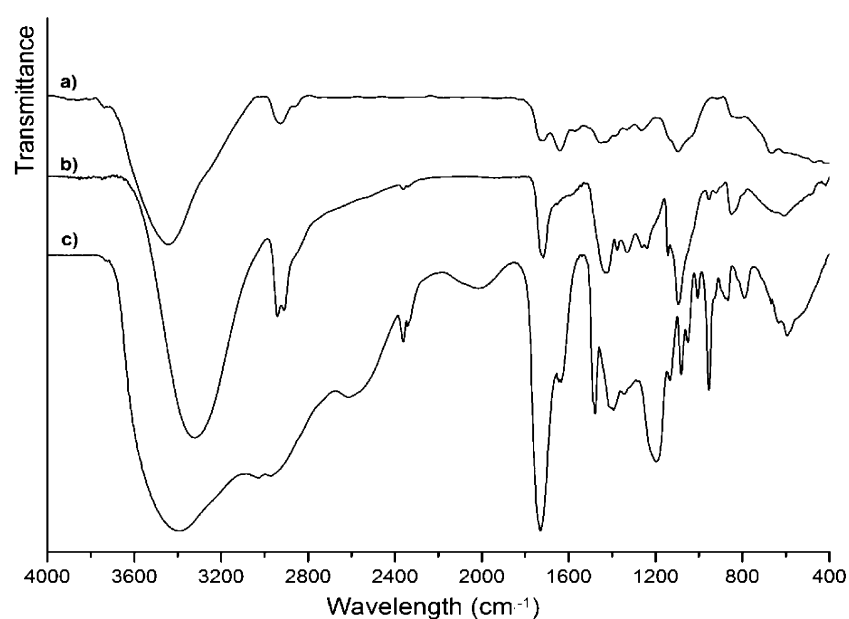

Figure 4. FTIR spectra of (a) pure PVA, (b) fibers with $9.8 \%(\mathrm{w} / \mathrm{v})$ PVA with $2 \%(\mathrm{v} / \mathrm{v}) \mathrm{ChCl}: \mathrm{CA}$, and (c) ChCl:CA.

in the fiber. Thus, by combining this information with the contrast difference present on TEM images, it is possible to validate that not only NADES is present in the fiber but that it is encapsulated within the fibers.

TGA Analysis. The results of the TGA analysis are presented in Figure 5. The NADES weight loss curve is

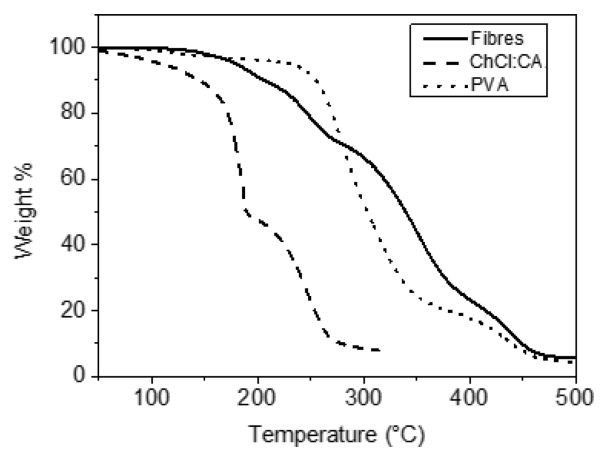

Figure 5. TGA spectra of pure ChCl:CA, pure PVA and fibers with $9.8 \%(\mathrm{w} / \mathrm{v})$ PVA with $2 \%(\mathrm{v} / \mathrm{v}) \mathrm{ChCl}: \mathrm{CA}$.

composed of two moments of weight loss, from 150 to $200{ }^{\circ} \mathrm{C}$ and from 200 to $270{ }^{\circ} \mathrm{C}$, corresponding to $\mathrm{CA}$ and $\mathrm{ChCl}$, respectively. As for PVA, the weight loss curve reveals that the thermal degradation starts at approximately $255^{\circ} \mathrm{C}$.

Choline chloride is a highly hygroscopic compound, and this property is also observed for the NADES mixture. The TGA curve for $\mathrm{ChCl}$ :CA denotes an almost constant mass loss before the first inflection point (degradation of citric acid), which can be attributed to the slow evaporation of water that has been absorbed by the sample.

The PVA-NADES fibers weight loss curve reflects the presence of its components, with weight losses from the NADES components and the PVA. Due to overlapping between the weight losses of $\mathrm{ChCl}$ and PVA, the fibers NADES composition was calculated from the weight loss of CA and determined to be $19.8 \%$. This value compares to the theoretical value of $21.3 \%$, expected if the electrospun fibers would retain the relative percentages of the source solution.

Mechanical Test. The mechanical properties of the fibers produced were measured in tensile mode. The elasticity of the fibers and their ability to recover their initial shape is a feature of major relevance, particularly for biomedical applications. The fibers show a Young's modulus of $0.062 \pm 0.012 \mathrm{MPa}$, a tensile stress of $18.28 \pm 4.2 \mathrm{MPa}$, and an elongation break of $93.88 \pm$ $6.9 \%$.

The mechanical properties of electrospun PVA fibers have been described in the literature. Franco and co-workers ${ }^{35}$ reported $40.71 \%$ tensile strain and $0.82 \mathrm{MPa}$ tensile stress for PVA fibers electrospun from a $12 \%$ aqueous solution. Another report, by Linh et al., refers to PVA fibers with $98 \%$ tensile strength and 0.5 MPa tensile stress. ${ }^{36}$ The values obtained show that the presence of the NADES component in the fibers did not compromise the mechanical properties of the fibers, which have very interesting mechanical properties. As seen before by FTIR analysis, there is an interaction between the DES and PVA. It is to be expected that some hydrogen bonds between PVA hydroxyl groups are broken and re-established with the DES components, more specifically with the chloride of choline chloride. This will have a plasticizing effect increasing the mobility of the PVA chains and consequently giving it a more ductile behavior. This behavior was already observed when doping natural-based polymers with ionic liquids. ${ }^{13,14,16}$

\section{CONCLUSION}

In this work, we developed a method for the production of PVA fibers by electrospinning for the encapsulation of deep eutectic solvents. ChCl:CA (1:1) was used as a model NADES. The working parameters for the electrospinning process were optimized and the mechanical properties of the produced fibers characterized. The electrospun fibers were analyzed and it was concluded by SEM that smooth and uniform fibers were obtained. By TEM analysis it was observed that the NADES was encapsulated in the fibers, which was confirmed by TGA analysis.

From this work, it was proved that functionalized fibers with NADES can be produced by electrospinning. This opens new opportunities for the application of these solvents in association with biocompatible polymers. By using NADES with active components, new delivery systems with high surface area can be produced.

\section{AUTHOR INFORMATION}

\section{Corresponding Author}

*A. Paiva. Tel.: +351 212949 681. Fax: + 351212948 385. Email: alexandre.paiva@fct.unl.pt.

\section{Author Contributions}

The paper was written through contributions of all authors. All authors have given approval to the final version of the paper.

\section{Notes}

The authors declare no competing financial interest.

\section{ACKNOWLEDGMENTS}

Alexandre Paiva is grateful for financial support from Fundação para a Ciência e a Tecnologia (FCT/MEC) through the grant SFRH/BPD/44946/2008. We further acknowledge the financial support of FCT/MEC through the project ENIGMA PTDC/EQU-EPR/121491/2010, and the project PEst-C/ EQB/LA0006/2013. We also acknowledge funding from the European Union's Seventh Framework Programme (FP7/ 2007-2013) under grant agreement $\mathrm{n}^{\circ}$ REGPOT-CT2012316331-POLARIS, and from the Project "Novel smart and biomimetic materials for innovative regenerative medicine approaches (Ref.: RL1 - ABMR - NORTE-01-0124-FEDER- 
000016)" cofinanced by the North Portugal Regional Operational Programme (ON.2 - O Novo Norte), under the National Strategic Reference Framework (NSRF), through the European Regional Development Fund (ERDF). This work was also partly funded by FEDER funds through the COMPETE 2020 Programme and National Funds through FCT - Portuguese Foundation for Science and Technology under the project UID/CTM/50025/2013.

\section{ABBREVIATIONS}

CA, citric acid

$\mathrm{ChCl}$, choline chloride

$\mathrm{ChCl}: \mathrm{CA}$, choline chloride:citric acid

FTIR, Fourier transform infrared spectrometry

NADES, natural deep-eutectic solvents

PVA, poly(vinyl alcohol)

SEM, scanning electron microscopy

TEM, transmission electron microscopy

TGA, thermogravimetric analysis

\section{REFERENCES}

(1) Anastas, P.; Eghbali, N. Green chemistry: principles and practice. Chem. Soc. Rev. 2010, 39 (1), 301-312.

(2) Paiva, A.; Craveiro, R.; Aroso, I.; Martins, M.; Reis, R. L.; Duarte, A. R. C. Natural Deep Eutectic Solvents - Solvents for the 21st century. ACS Sustainable Chem. Eng. 2014, 2, 1063.

(3) Smith, E. L.; Abbott, A. P.; Ryder, K. S. Deep eutectic solvents (DESs) and their applications. Chem. Rev. 2014, 114, 11060-11082.

(4) Zhang, Q.; De Oliveira Vigier, K.; Royer, S.; Jérôme, F. Deep eutectic solvents: syntheses, properties and applications. Chem. Soc. Rev. 2012, 41 (21), 7108-7146.

(5) Nkuku, C. A.; LeSuer, R. J. Electrochemistry in deep eutectic solvents. J. Phys. Chem. B 2007, 111 (46), 13271-13277.

(6) Dai, Y.; Witkamp, G. J.; Verpoorte, R.; Choi, Y. H. Natural deep eutectic solvents as a new extraction media for phenolic metabolites in carthamus tinctorius L. Anal. Chem. 2013, 85, 6272-6278.

(7) Durand, E.; Lecomte, J.; Villeneuve, P. Deep eutectic solvents: Synthesis, application, and focus on lipase-catalyzed reactions. Eur. J. Lipid Sci. Technol. 2013, 115, 379-385.

(8) Carriazo, D.; Serrano, M. C.; Gutiérrez, M. C.; Ferrer, M. L.; del Monte, F. Deep-eutectic solvents playing multiple roles in the synthesis of polymers and related materials. Chem. Soc. Rev. 2012, 41 (14), 4996-5014.

(9) Dai, Y.; van Spronsen, J.; Witkamp, G.-J.; Verpoorte, R.; Choi, Y. $\mathrm{H}$. Natural deep eutectic solvents as new potential media for green technology. Anal. Chim. Acta 2013, 766, 61-68.

(10) Choi, Y. H.; van Spronsen, J.; Dai, Y.; Verberne, M.; Hollmann, F.; Arends, I. W. C. E.; Witkamp, G.-J.; Verpoorte, R. Are natural deep eutectic solvents the missing link in understanding cellular metabolism and physiology? Plant Physiol. 2011, 156 (4), 1701-1705.

(11) Hayyan, M.; Hashim, M. A.; Al-Saadi, M. A.; Hayyan, A.; AlNashef, I. M.; Mirghani, M. E. S. Assessment of cytotoxicity and toxicity for phosphonium-based deep eutectic solvents. Chemosphere 2013, 93, 455-459.

(12) Hayyan, M.; Hashim, M. A.; Hayyan, A.; Al-Saadi, M. A.; AlNashef, I. M.; Mirghani, M. E. S.; Saheed, O. K. Are deep eutectic solvents benign or toxic? Chemosphere 2013, 90, 2193-2195.

(13) Duarte, A. R. C.; Silva, S. S.; Mano, J. F.; Reis, R. L. Ionic liquids as foaming agents of semi-crystalline natural-based polymers. Green Chem. 2012, 14, 1949.

(14) Martins, M.; Craveiro, R.; Paiva, A.; Duarte, A. R. C.; Reis, R. L. Supercritical fluid processing of natural based polymers doped with ionic liquids. Chem. Eng. J. 2014, 241, 122-130.

(15) Pimenta, A.; Baptista, A.; Carvalho, T.; Brogueira, P.; Lourenço, N.; Afonso, C.; Barreiros, S.; Vidinha, P.; Borges, J. P. Electrospinning of Ion Jelly fibers. Mater. Lett. 2012, 83, 161-164.
(16) Martins, M.; Aroso, I. M.; Reis, R. L.; Duarte, A. R. C.; Craveiro, R; Paiva, A. Enhanced performance of supercritical fluid foaming of natural-based polymers by deep eutectic solvents. AIChE J. 2014, 60 (11), 3701-3706.

(17) Wang, S.; Peng, X.; Zhong, L.; Jing, S.; Cao, X.; Lu, F.; Sun, R. Choline chloride/urea as an effective plasticizer for production of cellulose films. Carbohydr. Polym. 2015, 117, 133-139.

(18) Li, D.; Xia, Y. Electrospinning of Nanofibers: Reinventing the Wheel? Adv. Mater. 2004, 16 (14), 1151-1170.

(19) Li, Z.; Wang, C. Effects of Working Parameters on Electrospinning. In One-Dimensional Nanostructures: Electrospinning Technique and Unique Nanofibers; SpringerBriefs in Materials: Berlin/ Heidelberg, 2013; pp 15-29.

(20) Canejo, J. P.; Borges, J. P.; Godinho, M. H.; Brogueira, P.; Teixeira, P. I. C.; Terentjev, E. M. Helical twisting of electrospun liquid crystalline cellulose micro- and nanofibers. Adv. Mater. 2008, 20 (24), 4821-4825.

(21) Godinho, M. H.; Canejo, J. P.; Pinto, L. F. V.; Borges, J. P.; Teixeira, P. I. C. How to mimic the shapes of plant tendrils on the nano and microscale: spirals and helices of electrospun liquid crystalline cellulose derivatives. Soft Matter 2009, 5, 2772.

(22) Casper, C. L.; Yamaguchi, N.; Kiick, K. L.; Rabolt, J. F. Functionalizing electrospun fibers with biologically relevant macromolecules. Biomacromolecules 2005, 6 (4), 1998-2007.

(23) Zhang, C.; Yuan, X.; Wu, L.; Han, Y.; Sheng, J. Study on morphology of electrospun poly(vinyl alcohol) mats. Eur. Polym. J. 2005, 41 (3), 423-432.

(24) Kenawy, E.-R.; Abdel-Hay, F. I.; El-Newehy, M. H.; Wnek, G. E. Controlled release of ketoprofen from electrospun poly(vinyl alcohol) nanofibers. Mater. Sci. Eng., A 2007, 459 (1-2), 390-396.

(25) Mahato, I. Biomaterials for Delivery and Targeting of Proteins and Nucleic Acids; CRC Press: Boca Raton, FL, 2005.

(26) Fuertges, F.; Abuchowski, A. The clinical efficacy of poly(ethylene glycol)-modified proteins. J. Controlled Release 1990, 11 (13), 139-148.

(27) Juang, J.-H.; Bonner-Weir, S.; Ogawa, Y.; Vacanti, J. P.; Weir, G. C. OUTCOME OF SUBCUTANEOUS ISLET TRANSPLANTATION IMPROVED BY POLYMER DEVICE. Transplantation 1996, 61 (11), 1557-1561.

(28) Chen, D.-H.; Leu, J.-C.; Ting-Chia, H. Transport and hydrolysis of urea in a reactor-separator combining an anion-exchange membrane and immobilized urease. J. Chem. Technol. Biotechnol. 1994, 61 (4), 351-357.

(29) Hyon, S.-H.; Cha, W.-I.; Ikada, Y.; Kita, M.; Ogura, Y.; Honda, Y. Poly(vinyl alcohol) hydrogels as soft contact lens material. J. Biomater. Sci, Polym. Ed. 1994, 5 (5), 397-406.

(30) Ignatova, M.; Starbova, K.; Markova, N.; Manolova, N.; Rashkov, I. Electrospun nanofibre mats with antimicrobial properties from quaternised chitosan and poly (vinyl alcohol). Carbohydr. Res. 2006, 341 (12), 2098-2107.

(31) Park, J.-C.; Ito, T.; Kim, K.-O.; Kim, K.-W.; Kim, B.-S.; Khil, M.S.; Kim, H.-Y.; Kim, I.-S. Electrospun poly(vinyl alcohol) nanofibers: effects of degree of hydrolysis and enhanced water stability. Polym. J. 2010, 42 (3), 273-276.

(32) Ding, B.; Kim, H.-Y.; Lee, S.-C.; Shao, C.-L.; Lee, D.-R.; Park, S.-J.; Kwag, G.-B.; Choi, K.-J. Preparation and characterization of a nanoscale poly(vinyl alcohol) fiber aggregate produced by an electrospinning method. J. Polym. Sci., Part B: Polym. Phys. 2002, 40 (13), 1261-1268.

(33) Chhabra, R. P.; Richardson, J. F. Non-Newtonian Flow and Applied Rheology: Engineering Applications, 2nd ed.; Elsevier: Amsterdam, 2008.

(34) Fonseca, E.; Fábia, S.; Sander, H. Synthesis and Characterization of Poly (Vinyl Alcohol) Hydrogels and Hybrids for rMPB70 Protein Adsorption. Mater. Res. 2006, 9 (2), 185-191.

(35) Franco, R. A.; Sadiasa, A.; Lee, B. T. Utilization of PVPA and its effect on the material properties and biocompatibility of PVA electrospun membrane. Polym. Adv. Technol. 2014, 25, 55-65. 
(36) Linh, N. T. B.; Min, Y. K.; Song, H. Y.; Lee, B. T. Fabrication of polyvinyl alcohol/gelatin nanofiber composites and evaluation of their material properties. J. Biomed. Mater. Res., Part B 2010, 95B, 184-191. 